\title{
Design of a Distributed Food Traceability Platform and Its Application in Food Traceability at Guangdong Province
}

\author{
Haibiao luo, Yin Li, Dongcheng Liu, Yunxiong Ouyang, Feng Yuan \\ Institute of Software Application Technology, Guangzhou \& Chinese Academy of Sciences, Guangzhou 511458, China
}

\begin{abstract}
Food traceability is an important measure to secure food safety. This paper designed a food traceability platform based on distribution framework and implemented it in Guangdong province. The platform can provide traceability service, production and management service for food enterprise, provide forward and backward traceability of the whole cycle of food production and circulation, and provide various methods of food traceability for public. One characteristic of the platform is that it opens up the data flow among production, circulation and supervising departments, and builds a unified commodity circulation data pool. Based on the flow data pool, not only the production and circulation information of the food product can be traced, but also its inspection and quarantine information. Another characteristic of the platform is that its database and data interface were developed based on the fool electronic traceability standards formulated by the National Food and Drug Administration. Its interface standardization and compatibility with other food traceability platforms can thus be guaranteed. The platform is running at Guangdong province for key supervising products of Infant formula foods (including milk powder, rice flour, farina, etc), editable oil and liquor. The public can use the Guangdong food traceability portal, mobile APP, Wechat or the self-service terminals in the supermarkets to trace food products by scanning or input its traceability code or its product code and verify its authenticity. It will help to promote consumer confidence in food safety.
\end{abstract}

\section{Introduction}

Food security issue has become an important social problem worldwide. From the outburst of bovine spongiform encephalopathy (BSE) at the end of last century in Europe [1], detection of melamine in milk in China in 2008, to the horse meat incident in France in 2013[2], as well as the bird flu, the illegal cooking oil, the Sudan red and other food security incidents [3], all highlight the gravity of the food security situation. In 2015 a first ever estimates of the global burden of foodborne diseases by World Health Organization (WHO) [4] show almost 1 in 10 people fall ill every year from eating contaminated food and 420000 die as a result, children under 5 account for almost one third of deaths. World health statistics conducted by WHO [5] show that more than 100 countries are transitioning rapidly towards a greater proportion of deaths from noncommunicable diseases and injuries. In 22 under-developed countries, $70 \%$ or more of years of life lost (due to premature deaths) are still caused by infectious diseases and related conditions. Meanwhile, in 47 countries (mostly high-income), noncommunicable diseases and injuries cause more than $90 \%$ of years of life lost. These fully testify that food security is a very severe situation worldwide. Building food traceability systems, monitoring, managing and tracing food from farm to food production, processing and circulation in the market, is deem as an important method to guarantee food security and prevent food borne diseases [6-10].

Therefore countries in the world develop various food traceability systems. The first was beef products traceability and management system [11] built by European Union (EU) in 1997. And the opinion of traceability management was first proposed at that time. In 2002, EU further expanded the scope of traceability to all the food sold in EU. The US proposed "risk management from farm to table" [12] and asked food corporations to build food traceability system. Japan started to trace beef products at 2003 [13]. These food traceability system formed new non-tariff barriers to trade in effect. To answer the new changes in food security management and food trade, Australia, New Zealand, Canada and other countries developed traceability management of animal husbandry related products. China started to explore and study food traceability system since 2000 [14-16]. At first port commodity was chosen to experiment and then extended to cow, sheep, vegetables, etc.

The EAN•UCC system [17] proposed by EAN International and America Uniform Code Council is the most popular food track and trace system, and has been applied widely by EU and the US to traceability system of food, drink, meat and other products. The EAN•UCC system mainly include 3 parts: coding system, data carrier (bar code, for instance) and data exchange

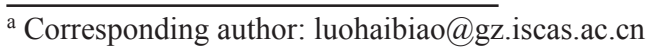


(Electronic Data Interchange, EDI for instance). Through the EAN•UCC system, every step of the food supply chain can be effectively marked and information among steps can be transmitted, interchanged and managed. Food therefore can be tracked and traced in efficient and effective ways. Netherlands built a comprehensive production chain management system called Integrale Keten Beheersing (IKB) [19], which is a quality detection and control system to ensure all important activities in production chains under control. The British government built the Cattle Tracing system (CTS) [20-21] to register cattle births and report cattle deaths and movements. The Australia's National Live Stock Identification System, NLIS [22] record livestock movements from its birth to slaughter by its permanent id system. Australia further established the Efficient Consumer Response Australia (ECRA) based on GS1 standards [23] to trace food, drinks and other products' supply chain. Canada first built the Canadian Livestock Tracking System (CLTS) [25] to track supply chain of livestock, especially cow. After its success, CLTS was further extended to track agricultural products and resulted in National Agriculture and Food Traceability System (NAFTS) [26].

In China, there are many food traceability systems. The largest is the State food (product) Safety Traceability platform 28, which was established by GS1 China [27] and started to collect product codes since 2007. Currently the total number of the traceable products in the platform is 71225540. The Public Service Platform of State Food Industry Corporation Credit [29] aims to improve public trust for Chinese food corporations by developing food industry credit system and evaluating corporation credit. It also provides food product traceability service for 6 infant formula milk powder manufactories. Reclamation of Agricultural Product Quality Safety Net [30] provides tracking and tracing service of agricultural products of 5 provinces. In addition, local governments also build their own food traceability systems. In Sichuan province, Agricultural Product Quality Safety Platform [31] was set up to record supply chain information of agricultural products (tea, lemon, mutton and some fruits), from source of raw materials, processing, inspection of finished products, logistics channel, to retail information electronically. Anhui Food Safety Traceability Platform [32] developed food traceability system of whole chain from raw materials to retail of infant formula milk powder, meat products, dairy products, edible vegetable oil and liquor. Shanghai Food Safety Traceability Platform [33] also built a traceability system of the whole chain of from raw material to retail of cereals, fruits, edible vegetable oil, livestock products, aquatic product, vegetable and dairy products based on Internet of Things technology. It works with local food supervision departments to import product supervision information. There are more food traceability systems developed by food corporations themselves or industry associations. For example, Bee Product Association built a bee product traceability system [34] aiming to promote transparency of bee product and improve consumer's trust. Yili Milk Corporation established a traceability system [35] that records every step of milk production process from cow breeding, logistics of product to retail. Pork Quality
Traceability system [36] provide traceability information to the public by Personal Digital Assistant (PDA) and mobile communication technology.

In conclusion, at present most food traceability system can only trace food production process including raw materials and manufacturing of one or a few food products. Their main purpose is for quality control and to satisfy food quality regulations. Product circulation and retail processes usually involve other corporations who will not report their product circulation information without large enough benefits or strong forces from outside. Government food supervision departments normally won't open their data to other parties. Therefore, most food traceability systems cannot provide product circulation information and inspection and quarantine information from government supervision departments.

Data structure and interfaces of food traceability system have not been standardized by state regulations and standards until recently the State Food and Drug administration issued a serials of standards [37-44] for food safety electronic traceability systems.

The food traceability platform proposed in this paper has the following characteristics:

(1) From paper research results, the food traceability platform designed in this paper is one of the few platforms that can provide traceability not only throughout the whole production and circulation chain process, but also inspection and quarantine information from government supervision departments.

(2) The platform has built a Unified Merchandise Circulation Data Pool (UMCDP), in which manufacturing enterprises, circulation enterprises, supervision departments could record product information of the whole production and circulation process based on electronic product code, traceability code and manufacturing time.

Based on UMCDP, platform users, including consumers, can trace not only product's normal information such as manufacturer, production date and address, but also its inspection and quarantine information. It promotes transparency of this product's supervision, which is usually rare to be seen but most requested by consumers to ensure the food product's quality and security.

Based on UMCDP, the platform can provide big data analysis of the whole food supply and circulation chain for enterprises of the food corporations, while most food traceability system can only provide food production information.

(3) The platform designs its food traceability information data structure, internet of things information service interfaces and Internet of Things Name Service interfaces based on the latest standards specified by the State Food and Drug administration to ensure standardization and universality.

(4) Most traceability systems are built based on the product coding rule of corporation itself or industry specification. The platform in this paper developed a multi-industry food traceability coding, separation, parsing and transforms mechanism. A unified IOT identification id can be created for various products based 
on this mechanism and achieve traceability for all the domestic food products.

\section{Material and Methods}

\subsection{Food Traceability Requirements for the Whole Production and Circulation Cycle of Food}

The whole production and circulation cycle of food can be divided into raw material phase, production phase, finished-product left factory phase, delivery and circulation phase, and sales terminal phase. It's required to collect data from all the phases. For big corporations, the data collection work is usually done by their own ERP system. For small corporations, a SaaS service provided by the platform in this paper can be used.

Table 1. Required management information in a full cycle of food production.

\begin{tabular}{|l|l|}
\hline A full cycle & \multicolumn{1}{c|}{$\mathbf{c}$ mm } \\
\hline Raw & $\begin{array}{l}\text { Supplier, incoming inspection, in } \\
\text { storage time, etc }\end{array}$ \\
\hline Production & $\begin{array}{l}\text { During production and manufacture } \\
\text { phase, key information of production, } \\
\text { inspection record, finished-product } \\
\text { information, storage information, etc }\end{array}$ \\
\hline $\begin{array}{l}\text { finished- } \\
\text { product }\end{array}$ & $\begin{array}{l}\text { Information about leaving factory, } \\
\text { delivery, distributor }\end{array}$ \\
\hline Circulation & $\begin{array}{l}\text { Information about left factory, in storage, } \\
\text { out of storage }\end{array}$ \\
\hline $\begin{array}{l}\text { Retail } \\
\text { Terminal }\end{array}$ & $\begin{array}{l}\text { Traceability code, product bar code, sale } \\
\text { time, etc }\end{array}$ \\
\hline
\end{tabular}

Normally liquor, edible cooking oil, infant formula foods have one or multiple identification information of Electronic Product Codes (EPC), production date or production batch, box code or traceability code. The traceability code is the only identity label for a merchandise item. The carrier of the traceability code can be two-dimension QR code, RFID or NFC. The manufacturer or distributor must report the complete product package information including quantity, manufactory date, box code or traceability code. The circulation enterprises or catering enterprises must report the package information of products when they are bought or sold. The platform provides three methods to track and trace a product: EPC + production date, box code or traceability code.

\subsection{Regulations and Standards}

This platform was designed according to regulations of GB/T 22003-2008 Food safety management systemsrequirements for bodies providing audit and certification of food safety management systems[37-38], Standard system for food and drug administration information[39] and Standard system for Internet of Things of the state key food (product) quality and safety traceability [40].

Data structure of the food safety electronic traceability identification information was designed according to Standard for data structure of food safety traceability identification [41]. This standard designs food traceability coding structure including The Global Language of Business (GS1), Electronic Product code (EPC) and China Food Safety Trace (CFST).

Database service interface was designed according to Standard for Interfaces of Internet of Things Information Service Database of Food Safety Electronic Traceability (IOTIS) [42] that designs the database interfaces through which food safety traceability applications interchange data and events through internet. In this paper, IOTIS interfaces are provided to food corporations to upload required data.

Electronic traceability name service was designed according to Standard of Internet of Things Name Service for Food Electronic Traceability (IOTNS) [43] that designs the system architecture of internet of things name service, terminal user query interface, IOTNS query interface and IOTNS registration interface. IOTNS is composed of coding service and IOT name service. Coding service is to decode the identification information uploaded by users. IOT name service is to decode IOT web address uploaded by users.

Internet of things discovery service was designed according to Standard of Internet of Things Discovery Service for Food Electronic Traceability (IOTDS) [44]. When information of a single merchandise item is located at different IOTIS, the address of this item can be achieved by IOTDS.

\subsection{System Design}

The system architecture of Guangdong Province Food Safety Traceability Platform is showed at figure. 1. Distributed architecture is chosen to build the distributed traceability center, on which the Corporation Traceability Data Interchange Service Module, Production \& Operation Supervision Module, Public Traceability Service Module. In the Corporation Traceability Data Interchange Service Module, SaaS platform was built for corporations to deploy data upload and interchange service or connect with its own ERP system or a third party traceability system. Based on IOT technology, data can be uploaded and integrated from phases of manufacture, circulation and retail. To the public, supervision departments and other food industry partners, various terminals including web portals, mobile APPs, self-service terminals, are provided to serve food traceability requests.

\subsection{Architecture of System Functioning}

The main components of the system functioning are food traceability service and food traceability data center.

1) Food traceability service: mainly corporation traceability data interchange service, production \& operation supervision service, public query service. The corporation traceability data interchange service covers the business requirements of production and circulation corporations. It provides management functions for events of production and circulation. 


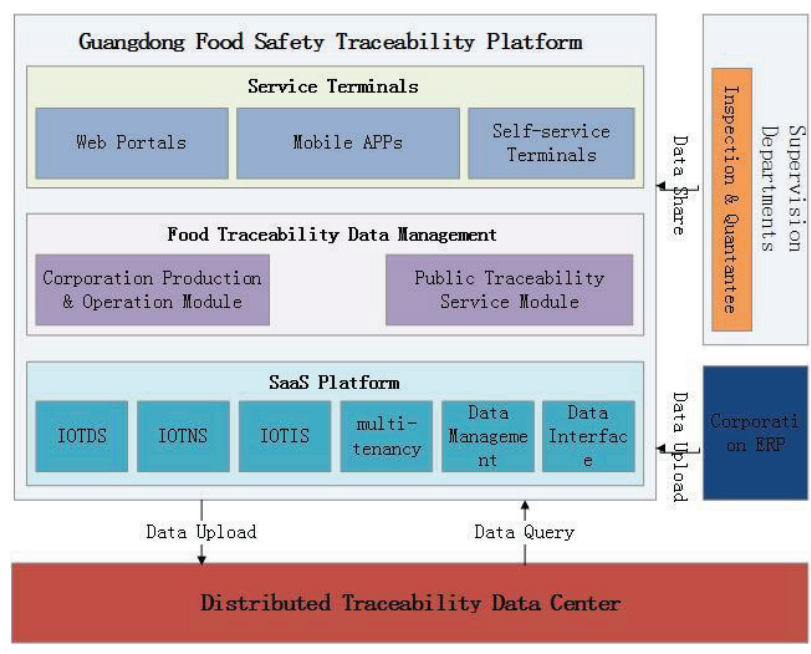

Figure 1. System of Framework

Production \& operation supervision service serves various levels of supervision departments and provide them food product management and supervision functions including corporation information management, product information management, product flow tracking, emergency operation, recall operation, risk prediction.

Public query service is to serve consumers and the public the product query request and provide genuine product manufacture information, delivery information, sales information, inspection information. The public can report quality and safety issues in the query terminals.

2) Food traceability data center: composed of two parts, basic data and business data. The basic data includes corporation information and production information which are produced during corporation and product registration. Business data includes production, circulation, inspection, retail information. The center provides interfaces for data upload, data interchange and data decoding.

\subsection{SaaS Platform for Multi-tenancy}

The platform has to serve various corporations with different business needs. Therefore it is crucial to be able to provide customization of software service based on tenancy. Tenancy is referred to the same group of users who have common demands for the platform [45]. The user rents software packages based on tenancy unit. The platform provides SaaS service to multi-tenancy and share human labor and device resource among tenants to lower the cost. The key technology to multi-tenancy is the multi-tenancy customization. The platform applied Metadata Driven Component-based Software Development method [46] to customize multi-tenancy.

The core of multi-tenancy customization based on Component-based Software Development method (CBSD) is extension point, by which business logics, interface logics and data entities of different tenancy can be substituted to build customized software. The business component can contain multi extension points and include extended functions for other components.

Metadata driven method is to develop generalization programs based on metadata, in which entity relationship showed at figure 2 is defined. MetaType defines metadata type and builds hierarchical structure by recursive parentType. MetaItem defines the metadata. Based on different metadata type, various business logics can be defined. For customization requests such as menu, business logic, entity and internationalization, the type of metadata can be defined correspondingly. Configuration of mutil-tenancy is stored as metadata. As deployment of a tenancy, addition, deletion or substitution of a present tenancy configuration metadata can build a new tenancy configuration.



Figure 2. Metadata driven entity relationship

\subsection{Service Framework based on IOT Technology}

The platform designs the service framework based on IOT technology and follows IOTIS specification as shown in figure 3 . The service framework has unified interfaces that food corporations upload and interchange their data through their own ERP system or ERP system provided by the SaaS service in the platform.

Traceability data are stored in corporation database as well as the traceability data center of this platform. The query address of all traceability data are registered in the traceability data center. Therefore, the province level platforms (Guangdong and Jiangsu Food Safety Traceability Platforms) are responsible for traceability query address. The state level food safety traceability platforms are responsible for the IP resolution of the query address.

This platform is a first attempt in the state to communicate query information between province level food traceability platforms. And it is also one of the first few food traceability platforms to specify the interfaces and data structures according to the latest food safety electronic traceability standards.

\subsection{Unified Merchandise Circulation Data Pool}

The platform records data from production, circulation, retail and supervisions and build a Unified Merchandise Circulation Data Pool (UMCDP), in which products are recorded and linked by product code, traceability code and production date.

By tracking retail state of the product, one can quickly find out counterfeit products if the total number of products be sold by retailers and in circulation state is higher than the number of production.

UMCDP data can also be used to analysis the market based on data from production, circulation and retail 
corporations and provide a more complete picture of the product flow situation.
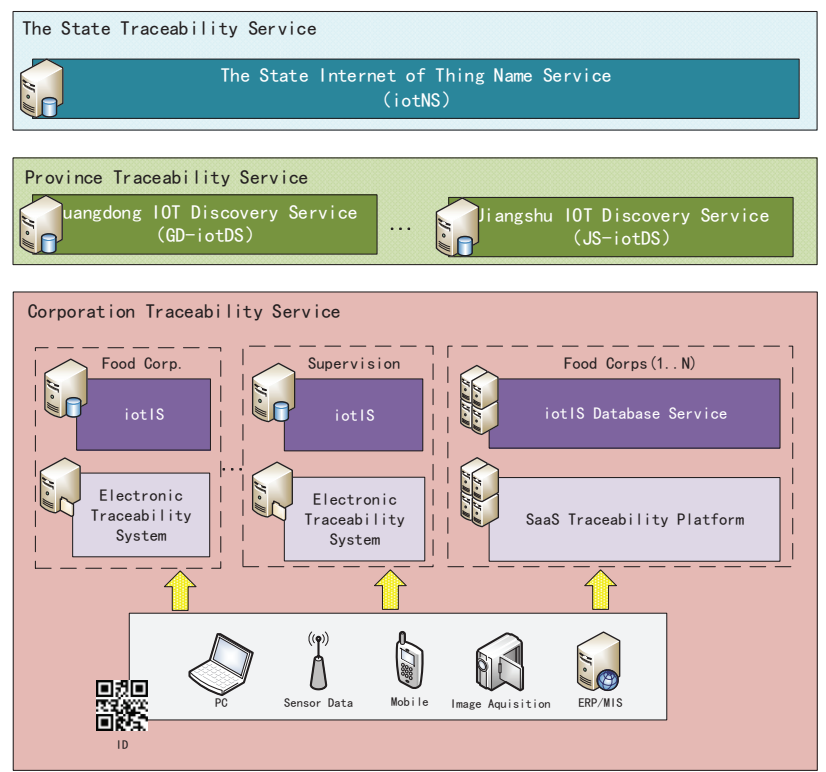

Figure 3. Framework of Internet of Things Service

\subsection{Public Traceability Service Terminals}

The food product query channels provided to the public are a web portal, public WeChat platform, mobile app and self-service terminals placed at supermarkets. Consumers can scan the product code or traceability code of the product using an APP, WeChat scanner, barcode scanner of the self-service terminals, or input the codes by hands in one of the terminals to get feedback of product information including product photo, place of origin, expiration date, inspection information, etc. If there is a safety or quality issue, one can report the issue through any of the terminals to supervision departments and relevant corporations.

\section{Results and Discussions}

\subsection{Application at Guangdong Province}

Guangdong Food Safety Traceability Platform was launched in 05/06/2016 and started to collect data from food corporations and supervision departments. The public traceability terminals were launched at the same time.

The web portal of the platform is: http://spsy.gdfda.gov.cn/. Public WeChat applet and mobile APPs for Android and Apple OS can be downloaded by searching Guangdong Food Traceabilityat the APP markets or from the web portal.

By the end of 12/31/2016, there were 883 food manufacturers, 36047 circulation and retail corporations, 4283 restaurants registered in the platform and started to report data regularly. There were 18497 domestic and imported products, 350 million traceability data, 122261 pieces of inspection reports. At the same time, public awareness of this platform has been growing. The APPs has been downloaded more than 100 thousand times and 400 thousand product queries through different terminals.

\subsection{Traceability Service for the Public}

Figure 4 shows the query results from the public WeChat applet. After scanning the QR code of a product, the front page of scanning result is shown in Fig. 4., from which one can see the name of the product, expiration date and traceability index. The traceability index is the result of the inspection report, expiration date and UMCDP data analysis results. In most cases, the index will be "good" in green. But if the inspection report is disqualified, the expiration date has passed, or UMCDP analysis indicates possible counterfeit the index will show warning information.

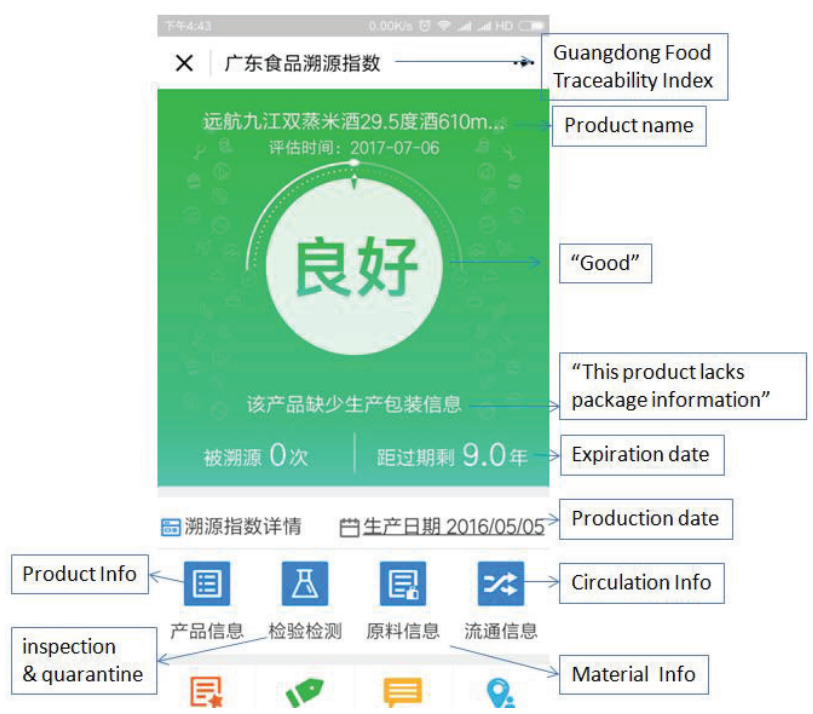

Figure 4. Query Page of a good product by WeChat applet "Guangdong Food Traceability"



Figure 5. Query Page of a disqualified product by WeChat applet "Guangdong Food Traceability"

At the bottom of the product page, there are four buttons (from left to right): product information, inspection \& quarantine, material information, circulation 
information. The product information page shows the product image and detail product information. Inspection $\&$ quarantine page contains inspection report issued by the local food supervision departments. The report is a pdf file and can be downloaded to learn the inspection detail. The material information page shows the detail information about the manufacturers. The circulation page shows the circulation corporations the product has gone through.

In an actual event that a food product was found disqualified during random inspections, the platform automatically received the inspection report and the traceability index was changed to "warning" in red and a sentence "The product's random inspection failed to pass, please be caution to buy" was shown below the warning sign.

\section{Conclusion}

This paper designed a food traceability platform for Guangdong province. It's built on distributed traceability data center where corporation data management, supervision service and public query service were established. SaaS platform were developed to support corporations, especially small corporations to build their food traceability system on it. Data will be collected from production, circulation, retail and supervision departments according to the latest state standards for food safety electronic traceability system. All traceability data enter into a data pool that links data from different parties together. The platform designs its food traceability information data structure, internet of things information ser-vice interfaces and Internet of Things Name Service interfaces based on the latest standards specified by the State Food and Drug administration to ensure standardization and universality. Unified IOT identification for varieties of product codes can help lower the communication barriers. Currently, the Guangdong Food Safety Traceability Platform can communicate with Jiangsu Food Safety Traceability Platform and the State food (product) Safety Traceability platform for food product query out of province.

Various query terminals have been developed to satisfy different needs. Within half of year after its launch, 350 million traceability data have been recorded and more than 400 thousand queries have been made. It indicates that there is urgent need within the public to trace food product information. It also means that there is serious trust issue for food industry. Hopefully, the food traceability system can increase the credit of food product and improve the trust.

\section{Acknowledgements}

This research was financially supported by the National Sci-tech Support Plan 2015BAK36B02 and 2015BAK36B06, Guangzhou Sci-tech Plan 201610010092 and 201604020101.

\section{References}

1. C.B. Xue, P.Y. Wang, J. Zhao., et al. J. of Food Safety \& Quality 7(7) 2815-2820 (2016)

2. H. Xie, L.I. Jun-Min, Food Res. \& Dev. 34(22) 122$125(2013)$

3. J. Y. Lin, Q. X. Zeng, Modern Food Sci. \& Tech. 22(4) 189-192 (2006)

4. WHO, In children under five who estimates nearly a third of food borne disease deaths worldwide http: //www.who.int/mediacentre/news/releases/2015/food borne-disease-estimates/en/ [2015-12-3]

5. WHO, World Health Statistics 2014: Large gains in life expectancy

http://www.who.int/mediacentre/news/releases/2014/ world-health-statistics-2014/en/ [2014-05-15].

6. S. Kinoshita, Systems Control \& Information. 0 133139 (2006)

7. R. Ward, D. V. Bailey, R. Jensen, Int. Food \& Agri. Man. Rev. 08(2) (2005)

8. Y. C. Choe, J. Park, M. Chung, Inf. Syst. Frontiers., 11(2) 167-179 (2009)

9. L. U. Opara, F. Mazaud. Outlook on Agri. 30(4) 239247 (2001)

10. L. U. Opara, Agri. Eng. Int.: The CIGR e-journal. (2004)

11. G. Lu. Comp. Appl. \& Soft. 27(1) 20-22 (2010)

12. E. H. Golan, B. Krissoff, F. Kuchler, Agri. Econ. Reports (2004)

13. K. Sugiura, T. Onodera, Veterinaria Italiana 44(3) 519-519 (2008)

14. L. Lin,Stand. Sci. 4:55-60 (2009)

15. X. S. Tong, Y. Wu, Log. Eng. \& Man. 32(1) 126-128 (2010)

16. Y. L. Fei, X. F. Xiao, X. M. Wu, China Collective Economy 1 84-85 (2011)

17. D. C. Bulterman, IEEE Computer Society Press, 2001.

18. T. Yue, Int. Conf. on E-Bus. and E-Gov. IEEE 1-3 (2011)

19. E. Kanis, A. F. Groen, K. H. D. Greef, J. of Agri. \& Env. Ethics 16(2) 137-162 (2003)

20. D. M. Green, R. R. Kao, Veterinary Record 161(13) 439-43 (2007)

21. CTS online. https://www.gov.uk/cattle-tracing-online

22. Australia's National Live Stock Identification System. https://www.nlis.com.au/

23. Australia GSI, Australia serving up safety and traceability http://www.ferret.com.au/c/GS1Australia (2010)

24. S. Kress, Australia Key Iss. \& Cha. Sup. Cha. Man. An Int. J. in Print 8 873-901 (2011)

25. Canadian Livestock Tracking System Services http://www.canadaid.com/CLTSServices.html

26. National Agriculture and Food Traceability System (NAFTS) http://www.ats-sea.agr.gc.ca/trac/syseng.htm

27. GS1 China http://www.ancc.org.cn/

28. The State food (product) Safety Traceability platform http://www.chinatrace.org/

29. The Public Service Platform of State Food Industry Corporation Credit http://www.foodcredit.org.cn/zs/zhuisu.html

30. Reclamation of Agricultural Product Quality Safety 
Net http://www.safetyfood.gov.cn/

31. Sichuan Agricultural Product Quality Safety Platform http://www.scfoodsafe.cn/

32. Anhui Food Safety Traceability Platform http://www.ahspy.cn

33. Shanghai Food Safety Traceability Platform http://www.shfda.org/

34. Bee Product Association built a bee product traceability system http://www.china-bee.org.cn

35. J. Cheng, Food Tech. 3 3-3 (2008)

36. B. H. Xiong, Y. T. Fu, Z. H. Lin, Chinese Agri. Sci. 42(1) 230-237 (2009)

37. The state administration of food and drug administration, http://www.sda.gov.cn/WS01/CL0087/171362.html 39 [2017-04-01]

38. The state administration of food and drug administration, GB/T 22003-2008 Food safety management systems-requirements for bodies providing audit and certification of food safety management systems (2009)

39. The state administration of food and drug administration, CFDAB/T 0101-2014 Standard system for food and drug administration information (2014)

40. The state administration of food and drug administration, Standard system for Internet of Things of the state key food (product) quality and safety traceability (Not released)

41. The state administration of food and drug administration, Standard for data structure of food safety traceability identification (Not released)

42. The state administration of food and drug administration, Standard for Interfaces of Internet of Things Information Service Database of Food Safety Electronic Traceability (IOTIS) (Not released)

43. The state administration of food and drug administration, Standard of Internet of Things Name Service for Food Electronic Traceability (IOTNS) (Not released)

44. The state administration of food and drug administration, Standard of Internet of Things Discovery Service for Food Electronic Traceability (IOTDS) (Not released)

45. H. L. Lin, Y. B. Han, Chinese J. of Comp. 33(10) 1881-1895 (2010)

46. Y. Li, F. Yuan, H. Wu, Comp. Eng. \& App. 51(9) 22-29 (2015)

47. X. Yang, J. Cao, App. Math. Mod. 34(11)3631-3641 (2010)

48. Y. Sun, W. Li, J. Ruan, Comm. in Theo. Phy. 58(5) 697-703 (2012) 